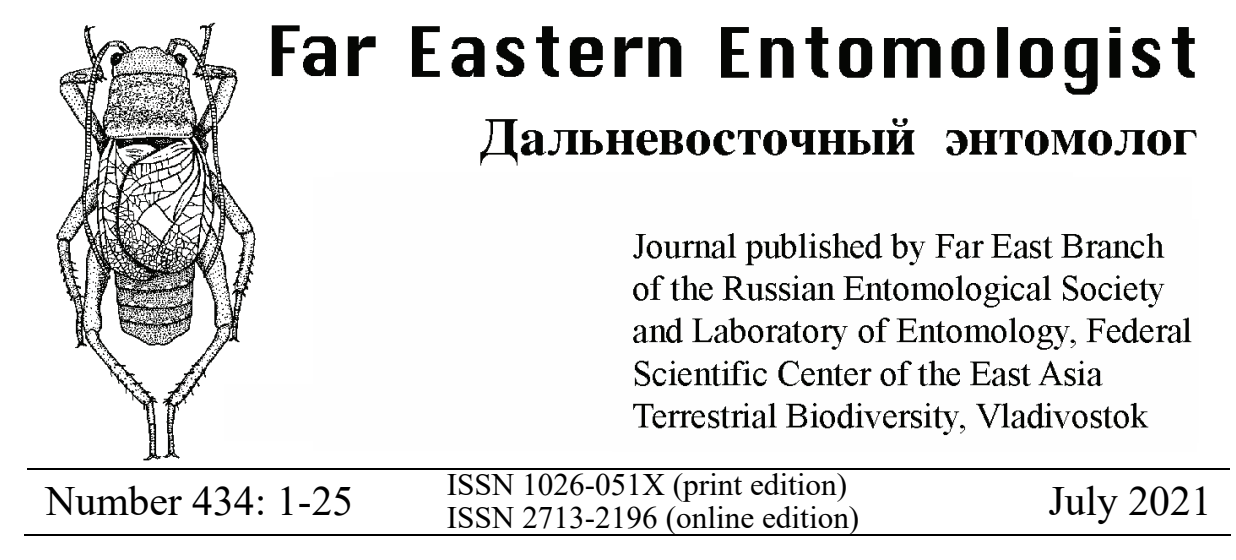

https://doi.org/10.25221/fee.434.1

http://zoobank.org/References/2A2352F6-0505-4F83-9040-56E8D5560D6E

\title{
TAXONOMY OF THE KATYDIDS (ORTHOPTERA: TETTIGONIIDAE) FROM EAST ASIA AND ADJACENT ISLANDS. COMMUNICATION 14
}

\begin{abstract}
A. V. Gorochov
Zoological Institute, Russian Academy of Sciences, Universitetskaya nab. 1, St. Petersburg 199034, Russia.E-mail: orthopt@zin.ru

Summary. The Indo-Malayan genus Lipotactes $\mathrm{Br}$.-W. is subdivided into nine subgenera: Lipotactes s. str.; Mortoniellus Griff., stat. n.; Prolipotactes subgen. n.; Dialipotactes subgen. n.; Neolipotactes subgen. n.; Miolipotactes subgen. n.; Sublipotactes subgen. n.; Analipotactes subgen. n.; Eulipotactes subgen. n. The following new species and subspecies of this genus are described from Borneo, Sumatra and Sulawesi: L. (L.) alienus lambir subsp. n.; L. (L.) a. similajau subsp. n.; L. (L.) a. kubah subsp. n.; L. (L.) sumatranus sp. n.; L. (P.) hamatus wartabone subsp. n.; $L .(P)$.$h . lorelindu subsp. n.; L$. (P.) $h$. irisovi subsp. n. Some former species taxa are reduced to subspecies ones: $L$. (S.) khmericus samkos Ingr., stat. n.; L. (S.) kh. saengeri Ingr., stat. n.; L. (S.) discus productus Ingr., stat. n. For several other taxa of this genus, new localities and some other data are given.

Key words: Orthoptera, Tettigoniidae, Tympanophorinae, Lipotactini, Lipotactes, new taxa, South-East Asia.

А. В. Горохов. Таксономия кузнечиков (Orthoptera: Tettigoniidae) из Восточной Азии и соседних островов. Сообщение 14 // Дальневосточный энтомолог. 2021. N 434. C. 1-25.
\end{abstract}


Резюме. Индомалайский род Lipotactes Br.-W. подразделен на девять подродов: Lipotactes s. str.; Mortoniellus Griff., stat. n.; Prolipotactes subgen. n.; Dialipotactes subgen. n.; Neolipotactes subgen. n.; Miolipotactes subgen. n.; Sublipotactes subgen. n.; Analipotactes subgen. n.; Eulipotactes subgen. n. Из Борнео, Суматры и Сулавеси описаны следующие новые вид и подвиды этого рода: L. (L.) alienus lambir subsp. n.; L. (L.) a. similajau subsp. n.; L. (L.) a. kubah subsp. n.; L. (L.) sumatranus sp. n.; L. (P.) hamatus wartabone subsp. n.; $L$. (P.) $h$. lorelindu subsp. n.; L. (P.) h. irisovi subsp. n. Некоторые бывшие видовые таксоны понижены в ранге до подвидовых: L. (S.) khmericus samkos Ingr., stat. n.; L. (S.) kh. saengeri Ingr., stat. n.; L. (S.) discus productus Ingr., stat. n. Для нескольких видов этого рода приведены новые местонахождения и некоторые другие данные.

\section{INTRODUCTION}

This paper is the fourteenth communication in the series of my papers on IndoMalayan and Papuan Tettigoniidae. The previous communication (thirteenth) is devoted to the tribe Agraeciini from the subfamily Conocephalinae (Gorochov, 2020); it contains a new subgeneric classification of the genus Anelytra Redtenbacher, 1891 and descriptions of twenty new taxa from this genus and from some other related genera. The present communication is about the tribe Lipotactini of the subfamily Tympanophorinae. This tribe possibly contains only one recent genus, Lipotactes Brunner-Wattenwyl, 1989, with numerous Asiatic species; here it is subdivided into nine subgenera, and some new data on their distribution and taxonomy, including descriptions of new species and subspecies taxa, are given. However, it is reasonable to note that sometimes this tribe is considered as a separate subfamily (Ingrisch, 1995, 2021; Tan et al., 2020), but such status of this taxon is insufficiently grounded, and here I prefer to use a more morphologically logical hypothesis about its belonging to the subfamily Tympanophorinae, because most of the differences proposed by the first author for the separation of his Lipotactinae from Tympanophorinae may be found within some other subfamilies of Tettigoniidae. The study is based on the material (including the types of new taxa) deposited at the Zoological Institute of the Russian Academy of Sciences, Saint Petersburg.

\section{NEW DATA ON TAXONOMY AND DISTRIBUTION}

\section{Subfamily Tympanophorinae}

Tribe Lipotactini

\section{Genus Lipotactes Brunner-Wattenwyl, 1898}

NOTE. This genus was united with the former genus Mortoniellus Griffini, 1909 by Hebard (1922). Later, different authors considered Lipotactes and Mortoniellus as one genus or as two genera (see Ingrisch, 1995), but in the latter paper, Mortoniellus was diagnosed as a distinct genus for some large species having the frons quadrangular, 
ovoid or triangular (but in reality, this structure is more or less intermediate in shape in almost all the species studied by me), the pronotum with a "transverse undulation" (but the pronotal shape is diverse in the congeners, included by Ingrisch in Mortoniellus, and possibly connected with their body size), and the male cercus with a distinct proximedial hook and a small tubercle on the base of this hook or near it (Figs 1, 2, 4, 5, 7, 8, 11, 12, 16-19, 21, 23). All these characters do not allow me to dependably distinguish Mortoniellus sensu Ingrisch from some of the species included by him in Lipotactes; moreover, Ingrisch also mentioned about this problem in the same paper.

Thus, I propose for a preliminary decision of this problem to reunite Lipotactes and Mortoniellus into one genus with nine subgenera having different structure of the male copulatory apparatus. However, L. azuriventer Karny, 1924 and L. vittifemur Karny, 1924 (described after a nymph and a female from South Sumatra) as well as L. longicauda Ingrisch, 1995 (described after a female from West Sumatra) are not included here in any subgenus. These species need to be restudied after the discovery of their males. Two other species, described after their males but unstudied by me, are possibly belonging to an unknown subgenus of Lipotactes s. 1.: L. laminus Shi et Li, 2009 and L. truncatus Shi et Li, 2009 (all from South China).

\section{Subgenus Lipotactes s. str.}

Type species Lipotactes alienus Brunner-Wattenwyl, 1898 (Malaysian Borneo).

NOTE. The type species of Lipotactes was described from a single female collected in northern part of Sarawak State in Malaysia (Brunner-Wattenwyl, 1898: "Flumen Baram [Baram River] in ins. Borneo"). The male of this species from Brunei was firstly described in details by Tan et al. (2020). Judging by the latter paper, this species has the hind femora with uniformly light proximal halves in the both sexes, and the proximedial hook of the male cercus practically as in L. alienus similajau subsp. n. (Figs 4, 5); thus, if the determination of the latter authors is correct, L. alienus as well as all the other species of this subgenus are characterized by the male last tergite lacking any distinct posteromedian lobe but having a very short posteromedian notch, the male epiproct normal (not strongly reduced and without additional lateral lobules), the male paraproct with a small finger-like or roundly conical lobule at the apex, the male cercus elongately conical and with the proximedial hook having an additional tubercle on its base or very near it, as well as the male genitalia completely membranous.

The nominotypical subgenus includes the following species (in primary binomen): type one; L. virescens Ingrisch, 1995 (Malay Peninsula); L. kabili Tan, Japir et Chung, 2020 (Malaysian Borneo); L. (L.) sumatranus sp. n.; possibly Mortoniellus digitatus Karny, 1931 (Sulawesi), M. digitatus var. concolor Kästner, 1933 considered by Ingrisch (1995) as a separate species (Sulawesi), M. ovatus Ingrisch, 1995 (Indonesian Borneo), M. macrognathus Ingrisch, 1995 (Malaysian Borneo) and M. parvus Ingrisch, 1995 (Sula Islands in Indonesia). 
Lipotactes (Lipotactes) alienus lambir Gorochov, subsp. $\mathbf{n}$.

http://zoobank.org/NomenclaturalActs/34C55F01-0E09-4B47-9FCD-6D164DE31677

Figs 1-3, 26-29, 77

MATERIAL. Holotype - $\hat{\sigma}$, Malaysia: Borneo I., Sarawak State, Lambir Hills National Park in environs of Miri Town, 100-300 m, forest, 29.III-1.IV 2012, A. Gorochov, M. Berezin, E. Tkatsheva, I. Kamskov. Paratypes: 2 กิ, 5 q, same data as for holotype.

DESCRIPTION. Male (holotype). Body moderately small for this genus. Coloration yellowish with following marks: epicranial dorsum between eyes and behind rostrum, a pair of dots in anterolateral corners of clypeus, narrow ring at apex of scape, almost entire pedicel, dorsal half of pronotum (except for a few marks on anterior half of disc: anterior margin and sinuate transverse line near it as well as a pair of short oblique stripes behind latter line dark brown; median longitudinal stripe between latter stripes as well as transverse stripe between anterior margin and sinuate line yellowish), moderately numerous dots on fore and middle femora and a group of dots in middle of dorsal part of hind femur, distal parts of spines and spurs on fore and middle tibiae as well as small spots on all tarsi, most part of abdominal tergites (except for yellowish areas on lateral parts and brown anterior stripe on dorsal part of each tergite) as well as epiproct and paraprocts, distal half of cercus and most part of its proximedial hook, and styles of genital plate light brown; antennal flagellum brown to dark brown; a pair of distolateral longitudinal spots and one subdistal dorsal longitudinal stripe on hind femur as well as spines and spurs on hind tibia brown; lateral margins of genital plate before styles brown to light brown (Figs $26,27)$. Scape approximately 1.5 times as wide as rostrum between antennal cavities; pronotum with hind lobe reaching distal edge of tegminal mirror; tegmina semitransparent with stridulatory membranes transparent; left tegmen with very short stridulatory vein, rather small both mirror and loop-like cell behind stridulatory vein, and narrow apical area (Fig. 77); last tergite with rather wide posteromedian notch; epiproct moderately small, roundly triangular; paraproct also small but with rather thin and short apical tubercle; cercus moderately short, with narrow (almost acute) apex and characteristic proximedial hook (this hook rather thin but not long, with slightly widened and curved but distinctly shorter dorsal lobule which located very near base of this hook and separated from it by moderately wide notch; Figs 1,2); genital plate with rather long and thin styles as well as with slightly concave posterior edge between styles (each style almost 1.5 times as long as distance between bases of styles; Fig. 1); genitalia completely membranous.

Variations. Other males barely lighter or barely darker, with posterior pronotal edge sometimes slightly not reaching distal edge of tegminal mirror, and with structure of cerci indistinguishable from that of holotype.

Female. General appearance as in males, but head dorsum with six darker (brown) longitudinal stripes between eyes, most part of anterior surface of epicranium rose, spots under rostrum (a pair) and under eyes (a pair) light brown, dark brown spots 
on dorsolateral parts of pronotum more numerous, outer side of proximal third of hind femur with brown or dark brown oblique (almost longitudinal) stripe, median band along all ptrothoracic and abdominal tergites light brown, band along each lateral part of these tergites brown to dark brown (but these tergites also with yellowish spots between these bands and on ventrolateral parts of 6-7 posterior abdominal tergites; Figs 28, 29), wings absent, posteromedian notch of last tergite distinctly narrower, genital plate short (transverse) and with apical part rather widely rounded but having small posteromedian notch (Fig. 3), and ovipositor with acute apex and a few very small denticles on ventrodistal edge.

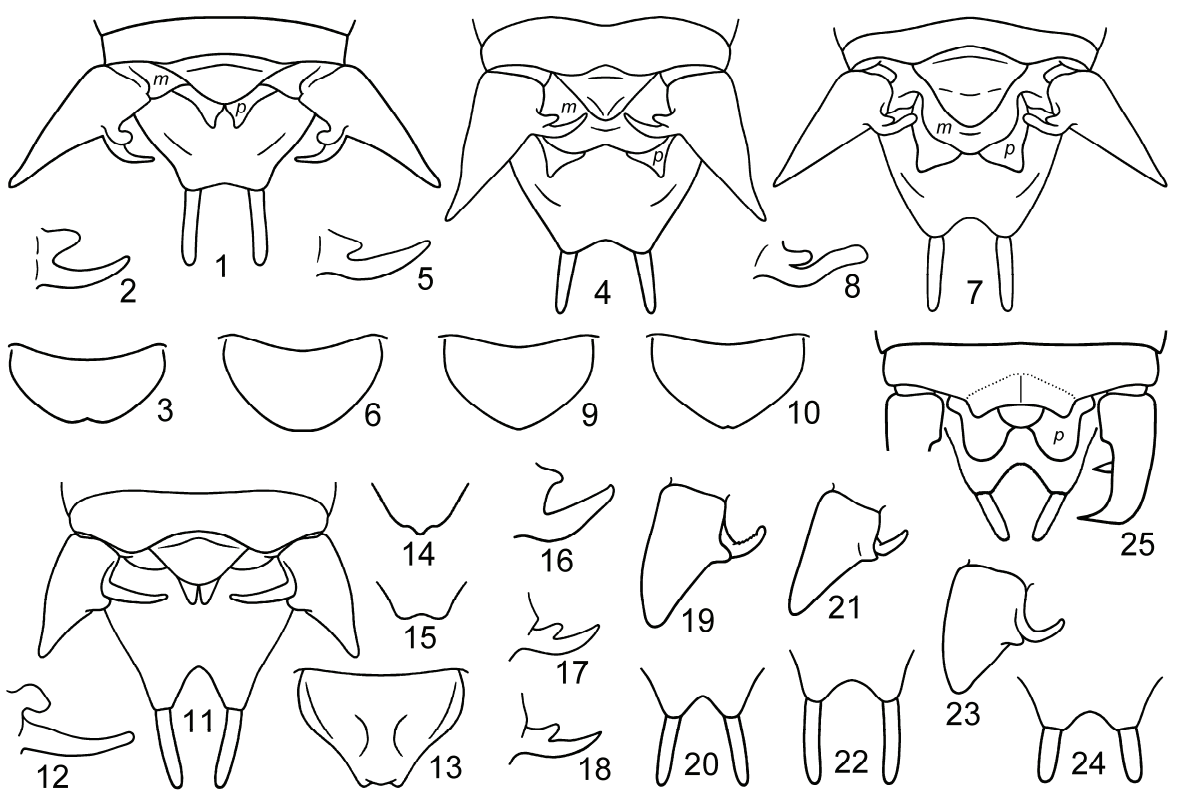

Figs 1-25. Lipotactes spp., schematically: 1-3-L. (Lipotactes) alienus lambir subsp. n.; 4-6 - L. (L.) a. similajau subsp. n.; 7, 8 - L. (L.) a. kubah subsp. n.; 9, $10-$ L. (L.) a. alienus? Br.-W.; 11-15 - L. (L.) sumatranus sp. n.; 16 - L. (L.) digitatus (Karny); 17, 18 $L$. (L.) virescens Ingr. from Malay Peninsula (17) and from Sumatra (18); 19-24 - L. (L.) macrognathus (Ingr.) from Sabah (19, 20 - Tawau Hills National Park; 21, 22 - Trus Madi Mt; 23, 24 - Sandakan Distr.); 25 - L. (Neolipotactes) montanus Ingr. Male abdominal apex from above $(1,4,7,11,25)$; proximedial hook of male left cercus (or this hook with tubercle or additional tubercle near it) from behind and slightly above $(2,5,8,12,16,17,18)$; female genital plate or its distal part from below $(3,6,9,10,13-15)$; male left cercus from above $(19,21,23)$; distal part of male genital plate from above $(20,22,24)$. Abbreviations: $m-$ membranous parts near cerci and around anus; $p$ - paraproct. [25 - after Ingrisch (1995), modified: without left cercus and some other details.]

MEASUREMENTS. Length (in mm). Body: ๙ $10-11$,

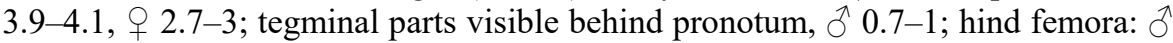
11-12, o 11-12.5; ovipositor 6.3-6.7. 
COMPARISON. The new subspecies differs from the nominotypical one in the male anal plate with the posteromedian notch somewhat less deep, the dorsal lobule (tubercle) of the male cercal proximedial hook slightly more widened and curved, the posteromedian edge of the male genital plate less deeply notched, the female hind femur with the proximal third having a dark stripe on its outer surface, and the female genital plate insignificantly shorter and more widely rounded apically (for comparison see Figs 3 and 9, 10). It is possible also that these subspecies may be two different species.

ETYMOLOGY. This new subspecies is named after Lambir Hills National Park where its type material was collected.

Lipotactes (Lipotactes) alienus similajau Gorochov, subsp. n.

http://zoobank.org/NomenclaturalActs/1F069938-17BD-4042-8BF0-EE5279AFCF58

Figs 4-6, 30-33, 78

MATERIAL. Holotype - $\widehat{\jmath}$, Malaysia: Borneo I., Sarawak State, $\sim 30 \mathrm{~km}$ from Bintulu Town, Similajau National Park, $3^{\circ} 25^{\prime} 26^{\prime \prime} \mathrm{N}, 113^{\circ} 13^{\prime} 59^{\prime \prime} \mathrm{E}$, primary forest not far from sea, almost sea level, 12-16.XI 2016, A. Gorochov, M. Berezin, E. Tkatsheva, I. Kamskov, N. Grigoreva. Paratypes: 1 ग, 2 , , same data as for holotype.

DESCRIPTION. Male (holotype). Size, coloration and structure of body very similar to those of $L$. (L.) a. lambir, but some differences present: rostrum between and around lateral ocelli light brown; head dorsum behind rostrum with six longitudinal light brown bands and narrower yellowish stripes between them; pronotum with almost yellowish disc having dark ornament as in L. (L.) a. lambir, but posterior half of hind pronotal lobe and median area between dark oblique stripes completely light brown (Figs 30,31); genital plate yellowish with light brown styles and traces of darkenings on lateral margins behind styles; tegmina almost identical to those of this subspecies (Fig. 78); last tergite with somewhat narrower and slightly deeper posteromedian notch; cercus with dorsal lobule (tubercle) at base of proximedial hook clearly less widened and almost not curved as well as separated from other branch of this hook by distinctly smaller notch; posterior edge of genital plate between styles more concave (Figs 4, 5).

Variations. Second male with transverse light brown area on pronotal disc behind dark oblique stripes, with darkish dots on middle femur almost indistinct, and with apical part of genital plate barely (but almost completely) darkened (cerci practically identical to those of holotype in structure).

Female. General appearance as in L. (L.) a. lambir including presence of dark stripe on outer surface of proximal third of hind femur, but genital plate almost as in L. (L.) a. alienus in length and without any apical notch (Figs 6, 32, 33).

MEASUREMENTS. Length (in mm). Body: $\widehat{\jmath}$ 9-10.5, 9 9.5-11.5; pronotum: त) 3.8-4, o 2.9-3.1; tegminal parts visible behind pronotum, ô 0.6-0.7; hind femora: ○े 10.5-11, q 11-12; ovipositor 6.5-6.7. 
COMPARISON. The new subspecies is most similar to L. (L.) a. lambir but distinguished by the male cercal proximedial hook with the dorsal lobule smaller and less curved as well as less separated from another branch of this hook, and by the female genital plate somewhat longer and without any apical notch (for comparison see Figs 3 and 6). From the nominotypical subspecies, L. (L.) a. similajau differs in the female hind femur with a distinct dark outer stripe on its proximal third, and in the female genital plate with its apical part more widely rounded (see Figs 6 and 9, 10.

ETYMOLOGY. The new subspecies is named after Similajau National Park, its type locality.

Lipotactes (Lipotactes) alienus kubah Gorochov, subsp. n. http://zoobank.org/NomenclaturalActs/AB6BD62C-7BA3-40B3-BA77-A94EDFCB46CC Figs $7,8,34,35,79$

MATERIAL. Holotype - $\hat{\sigma}$, Malaysia: Borneo I., Sarawak State, Kubah National Park on Matang Mt near Kuching City, 200-500 m, primary forest, 27.XI-1.XII 2016, A. Gorochov, M. Berezin, E. Tkatsheva, I. Kamskov.

DESCRIPTION. Male (holotype). Size, coloration and structure of body similar to those of $L$. (L.) a. lambir and $L$. (L.) a. similajau but with following differences: head with rostrum and dorsum almost uniformly yellowish; pronotum yellowish with brown anterior margin of disc and interrupted sinuate transverse line on disc near this margin as well as a pair of short oblique lines slightly behind previous (sinuate) line; fore and middle femora uniformly yellowish; hind femur also uniformly yellowish but with brown apex and a pair of dark brown longitudinal spots on inner and outer surfaces very near this apex (almost as in L. a. alienus); rest of body yellowish with more or less light brown majority of abdominal tergites and sternites (in living condition, latter sternites possibly lighter), cercal and paraproctal apices, cercal proximedial hooks, median part of epiproct, and styles of genital plate, as well as with brown dorsum of last tergite (Figs 34, 35); tegmina with slightly larger loop-like cell behind stridulatory vein and wider apical area as well as somewhat longer (moderately short) stridulatory vein of left tegmen (Fig. 79); last tergite with posteromedian notch as wide as in $L$. (L.) a. lambir and almost as deep as in $L$. (L.) $a$. similajau; proximedial cercal hook with ventral branch as long as in these subspecies but having barely widened (not narrowed) apical part, and with dorsal lobule intermediate between such lobules of above-mentioned taxa in shape but almost pressed to ventral cercal branch (Figs 7,8); posteromedian notch of genital plate between styles even deeper than in L. (L.) a. similajau (Fig. 7).

Female unknown.

MEASUREMENTS. Length (in mm). Body 11; pronotum 4.2; tegminal parts visible behind pronotum 0.6 ; hind femora 11.7.

COMPARISON. The new subspecies differs from the nominotypical one in the male tegmina having the apical area wider, and in the male cercal proximedial hook with a widened apex of its ventral branch and with the dorsal lobule almost pressed to the latter branch. From all the other subspecies of this species, $L$. (L.) a. kubah is distinguished by the same characters of the male tegmina and cerci, as well as by 
the stridulatory vein of the left tegmen longer, the loop-like tegminal cell larger, the body coloration lighter and more uniform, the male last tergite with the posteromedian notch wider or deeper, and the male genital plate with the posteromedian notch deeper (see Figs 1, 4 and 7).

ETYMOLOGY. The new subspecies is named after Kubah National Park where it was collected.

\section{Lipotactes (Lipotactes) alienus alienus? Brunner-Wattemwyl, 1898}

Figs 9, 10, 40

MATERIAL. Malaysia: 2 , , Borneo I., Sarawak State, Mulu National Park not far from borders with Brunei and Indonesia, 100-300 m, forest, 24-27.III 2012, A. Gorochov, M. Berezin, E. Tkatsheva, I. Kamskov.

NOTE. These two females are in accordance to the females, described by Brunner-Wattenwyl (1898) and Ingrisch (1995) from the northern part of Sarawak and from the nearest part of Sabah, as well as to those of Tan et al. (2020) from Brunei (including the absence of any dark outer stripe on the hind femur proximal third; Fig. 40). However, one of my females has its genital plate without any apical notch, but this plate in my second female is with a very small apical notch (Figs 9, 10). Here this subspecies is recorded from a new locality situated not far from all the other known localities of this subspecies.

\section{Lipotactes (Lipotactes) kabili Tan, Japir et Chung, 2020}

Fig. 81

MATERIAL. Malaysia: 2 ๙, 2 ㅇ, Borneo I., Sabah State, Tawau Hills National Park near Tawau Town, 200-400 m, forest, 14-20.V 2013, A. Gorochov, M. Berezin, V. Gorochova, E. Tkatsheva; 1 o, same data, but 6-14.III 2014, M. Berezin.

NOTE. The characters of these specimens are very similar to those indicated by Tan et al. (2020) in the first description of this species. However: my males have uniformly light proximal halves of the hind femora, and the left tegmen with the proximedial lobe somewhat more angularly projecting; my females have a clearly lighter (light brown) stripe on the outer surface of the hind femur, and the genital plate lacking a notch at the apex. Thus, my specimens and the types of this species from Sandakan District of Sabah may belong to more than one subspecies. It is interesting that the male cercal proximedial hooks of this species are almost identical to those of $L$. (L.) a. alienus and $L$. (L.) a. similajau, although the male tegminal stridulatory apparati of these species are very different (see Figs 77-79 and 81).

\section{Lipotactes (Lipotactes) virescens Ingrisch, 1995}

Figs $17,18,82-84$

MATERIAL. Malay Peninsula: $1 \hat{\jmath}, 1$, Thailand, Surat Thani Prov., $\sim 40 \mathrm{~km}$ WSW of Phanom Town, environs of Khao Sok National Park, forest, 20-29.VII 1996, A. Gorochov; 1 ô, 1 \&, Malaysia, Pahang State, Taman Negara National Park 


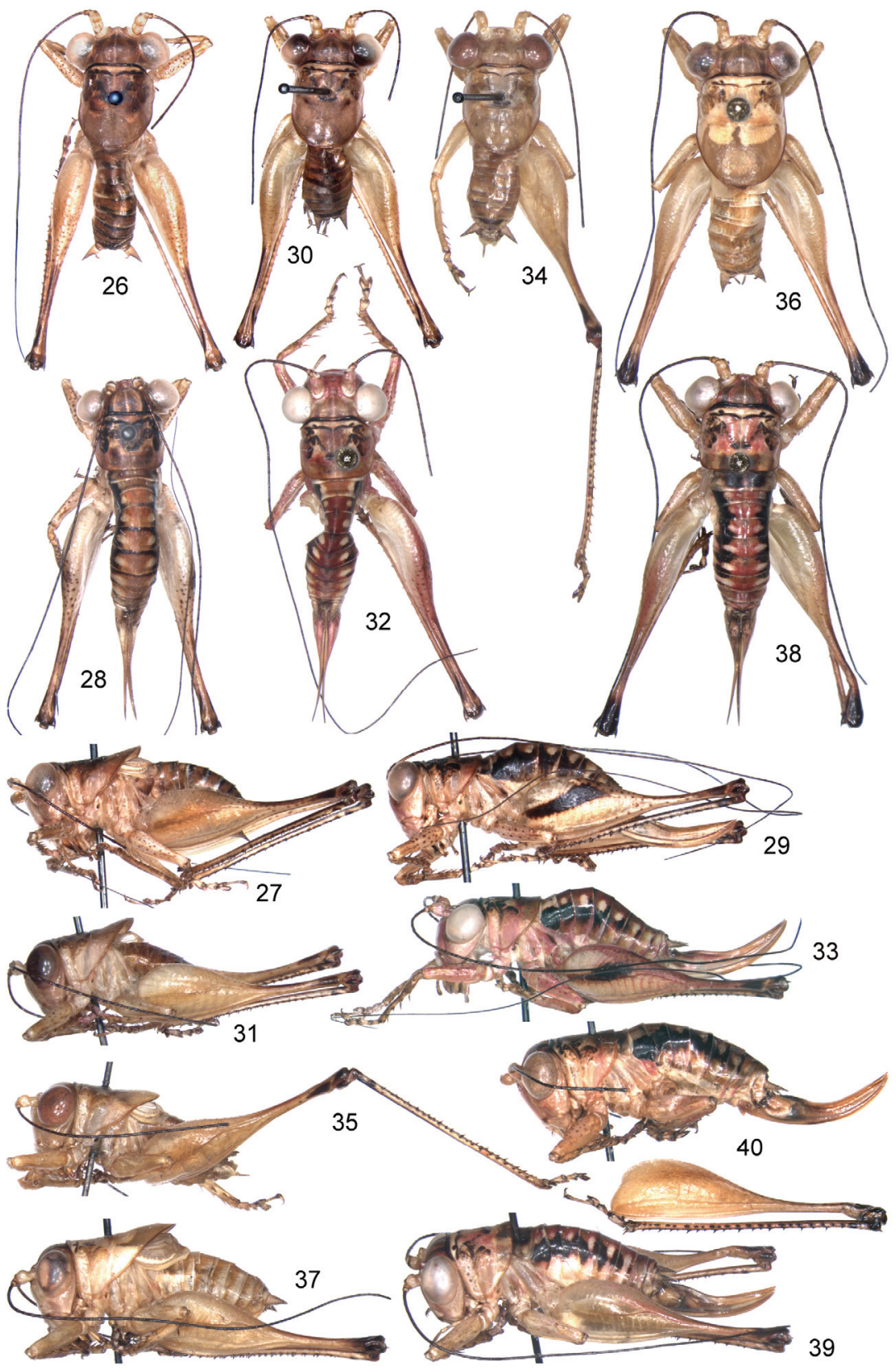

Figs 26-40. Lipotactes spp.: 26-29-L. (Lipotactes) alienus lambir subsp. n.; 30-33-L. (L.) a. similajau subsp. n.; 34, $35-$ L. (L.) a. kubah subsp. n.; 36-39-L. (L.) sumatranus sp. n.; $40-L$. (L.) a. alienus? Br.-W. with its hind leg shown separately under rest of body. Body of male $(26,27,30,31,34-37)$ and of female $(28,29,32,33,38-40)$ from above or from side. 
on Tembeling River, $\sim 100 \mathrm{~m}$, primary forest, 28.XI-5.XII 2014, A. Gorochov, M. Berezin, E. Tkatsheva. Indonesia: 3 o, 1 क , Sumatra I., West Sumatra Prov., $\sim 20$ $\mathrm{km}$ E of Sasak Town, environs of Harau Valley National Park, equator, $\sim 600 \mathrm{~m}$, 24-26.XI 1999, A. Gorochov.

NOTE. These specimens are very similar to each other and to the original description (Ingrisch, 1995). The males and females from Malay Peninsula are almost identical to the types of this species (from Thailand) in the body coloration (including that of the hind femur proximal half, which is almost completely light brown in male and with a dark longitudinal outer stripe in female) and in the presence of a very short but distinct additional tubercle on the basal part of the male cercus (Fig. 17); however, the male from Malaysia has the left tegmen with a somewhat wider membranous area between its mirror and lateral field as well as with a shorter and wider apical area (Fig. 83). All the males from Sumatra have the left tegmen almost as in my Thailandian male (Figs 82 and 84), but their cercus is with the abovementioned additional tubercle almost indistinct (Fig. 18), and the hind femur of my Sumatran female is without any dark stripe on its proximal half. These differences allow me to propose that my specimens may belong to two or three subspecies; however, I have only one male from each of the localities in Malay Peninsula and one female from Sumatra, i.e. this material is insufficient for such decision.

\section{Lipotactes (Lipotactes) sumatranus Gorochov, sp. $\mathbf{n}$.}

http://zoobank.org/NomenclaturalActs/04AB18D1-0633-4E82-8B6B-366D18EB7CE5

Figs 11-15, 36-39, 80

MATERIAL. Holotype - $\hat{\delta}$, Indonesia: Sumatra I., Aceh Prov. near border with North Sumatra Prov., environs of Ketambe Vill. on Alas River near Gunung Leuser National Park, $3^{\circ} 41-42^{\prime} \mathrm{N}, 9^{\circ} 38-39^{\prime} \mathrm{E}, 300-500 \mathrm{~m}$, primary forest, 15-24.IV 2018, A. Gorochov, M. Berezin, I. Kamskov, E. Tkatsheva. Paratypes: 1 O, 2 ㅇ, same data as for holotype; 1 , same country and island, North Sumatra Prov., $\sim 80$ $\mathrm{km} \mathrm{W}$ of Medan City, environs of Bukit Lawang Vill. on Bohorok River near Gunung Leuser National Park, $3^{\circ} 32-33^{\prime} \mathrm{N}, 9^{\circ} 6-7^{\prime} \mathrm{E}$, secondary forest, 6-14.IV 2018, A. Gorochov, M. Berezin, I. Kamskov, E. Tkatsheva.

DESCRIPTION. Male (holotype). Body medium-sized for this genus but slightly larger than in $L$. (L.) alienus. Coloration yellowish with following marks: head with two small brownish rose spots on rostrum, light brown dorsum between eyes (this light brown area with median yellowish line and a pair of brown spots near eyes) and a pair of dots in dorsolateral corners of clypeus as well as posterolateral margins of epicranium, brown apices of palpi as well as narrow rings on scape and pedicel around their apices, and dark brown antennal flagellum; pronotum with dark brown anterior margin of disc, a pair of sinuate brown transverse lines on disc near this edge, two pairs of brown to light brown dots around latter lines, and light brown posteroventral and posterior margins of hind pronotal lobe; legs with light brown area on dorsal part of fore tibia as well as distal parts of spines and spurs on fore and 
middle tibiae, brown distal (apical) portion of hind femur and small spots on hind tibia as well as spines and spurs of this tibia, and brown to light brown marks on all tarsi; most part of each tegmen semitransparent to transparent; abdomen with light brown transverse stripe (band) on each tergite, but last tergite with such band darker (almost brown); cercus with light greyish brown distal portion, proximedial hook and tubercle near it; genital plate with light grey styles (Figs 36, 37). Scape almost 1.5 times as wide as distance between antennal cavities; posterior edge of pronotum reaching almost apical areas of tegmina; left tegmen with mirror relatively longer than in $L$. (L.) alienus and $L$. (L.) kabili as well as with stridulatory vein intermediate between these species in length (Fig. 80); last tergite with moderately wide and deep posteromedian notch; epiproct normally developed, triangularly rounded; paraprocts with finger-like but short and almost conical apical projections; cercus short, with almost straight proximedial hook, and with tubercle near it rather large and semilamellar but having curved distal part (medial surface of this tubercle distinctly concave) and connected with low medial keel on proximal cercal part as well as completely separated from proximedial hook (Figs 11, 12); genital plate with very deep posteromedian notch and rather long styles (Fig. 11); genitalia completely membranous.

Variations. Second male with eyes having numerous greyish brown spots, genae under eyes having rose tinge, all marks on anterior half of pronotal disc brown to dark brown, and genital plate with barely wider and more rounded posteromedian notch.

Female. Body coloration distinguished from that of males by following peculiarities: presence of rose tinge on epicranium under rostrum, on fore and middle femora, and on hind tibia; intensely rose rostrum and two pairs of longitudinal stripes on head (medial stripes running from rostrum to posterior epicranial edge, lateral ones located along dorsomedial edges of eyes) as well as anterior two thirds of pronotum (lower parts of this area lighter); almost reddish rose dorsal and outer longitudinal stripes on hind femur as well as median (longitudinal) band on abdomen; reddish brown subdistal part of hind femur; more distinct dark marks on pronotum; almost blackish both a pair of areas on central part of metanotum and a pair of lateral bands running along previous (dorsal) band and interrupted distally (Figs 38, 39). Body structure similar to that of $L$. (L.) alienus but with some characteristic features: tegmina very strongly reduced, in shape of tiny lobules completely hidden under posterior part of pronotum; genital plate with slightly more elongated and narrowed distal part having a pair of small or very small apical lobules and often median lobule between them (latter lobule not projecting behind previous lobules or slightly projecting behind them; Figs 13-15); ovipositor somewhat shorter (hind femur approximately 2 times as long as ovipositor).

MEASUREMENTS. Length (in mm). Body: $\widehat{\delta} 11-12$, + 11.5-12.5; pronotum: o $5.4-5.8$, ㅇ 3.2-3.4; tegminal parts visible behind pronotum, 0 0.5-0.6; hind femora: $\overbrace{}^{\uparrow} 11.9-12.6$, o $12.7-13$; ovipositor 6.2-6.5.

COMPARISON. The new species is distinguished from all the previous species of this subgenus by the tegminal mirror of the left tegmen more longitudinal, and/or by some characteristic features of the male cerci (the proximedian hook straight; the 
tubercle near it semilamellar, curved, clearly separated from this hook, having concave medial surface, and connected with the low proximedial keel on the cercus) and of the genital plate in the both sexes (this plate with the posteromedian notch deeper in male, and with the distal part elongately narrowed in female). From $L$. (L.) macrognathus, L. (L.) digitatus, L. (L.) concolor, L. (L.) ovatus and L. (L.) parvus, the new species differs also in the less uniformly light coloration; and from L. azuriventer, L. vittifemur and L. longicauda (described from more southern territories of Sumatra but after a male nymph or females), in less spotted (less striped) anterior epicranial surface and/or legs, or in the ovipositor shorter than that of the latter species (the hind femur is approximately 1.5 times as long as ovipositor in L. longicauda and almost 2 times, in the new species).

ETYMOLOGY. This species name is originated from Sumatra I. where its type locality is situated.

Lipotactes (Lipotactes) macrognathus (Ingrisch, 1995), comb. nov. Figs 19-24

MATERIAL. Malaysia: $1 \hat{\jmath}$, Borneo I., Sabah State, Sandakan Division, environs of Sukau Vill. on Kinabatangan River $(\sim 35 \mathrm{~km}$ from sea), $\sim$ sea level, forest, 9-13.V 2013, A. Gorochov, M. Berezin, E. Tkatsheva; 1 đ, same island and state, Tawau Hills National Park near Tawau Town, 200-400 m, forest, 14-20.V 2013, A. Gorochov, M. Berezin, V. Gorochova, E. Tkatsheva; 1 त, same island and state, Trus Madi Mt, 1000 m, forest, 13-25.V 2007, A. Gorochov.

NOTE. This species was originally described from Sabah State of Malaysia (Borneo I.) and inside the "genus" Mortoniellus (Ingrisch, 1995). Here it is transferred to the nominotypical subgenus of the genus Lipotactes and recorded from some other localities of this island. It is interesting, but all my males are collected in different localities and having small differences in the structure of their cerci and genital plate (Figs 19-24). They may belong to different subspecies, but this material is very insufficient for their description.

Lipotactes (Lipotactes) digitatus (Karny, 1931)

Fig. 16

MATERIAL. Indonesia: 1 $\precsim$, Buton I. very near southeastern part of Sulawesi I., $\sim 40 \mathrm{~km}$ NNE of Baubau Town, Lambusango Reserve, 250-300 m, forest, 5 $11^{\prime} 43^{\prime \prime} \mathrm{S}$, $122^{\circ} 52^{\prime} 35^{\prime \prime} \mathrm{E}, 25-26 . X I$ 2015, A. Gorochov, M. Berezin, I. Kamskov, E. Tkatsheva; 1 q, same country, southeastern part of Sulawesi I., $30 \mathrm{~km}$ SE of Kendari City, environs of Moramo Waterfall, forest on hills, $4^{\circ} 13^{\prime} 33^{\prime \prime} \mathrm{S}, 122^{\circ} 44^{\prime} 9^{\prime \prime} \mathrm{E}, 29 . \mathrm{IX}$.2015, A. Gorochov, M. Berezin, I. Kamskov, E. Tkatsheva.

NOTE. This species was originally described from the central part of Sulawesi and inside the "genus" Mortoniellus (Karny, 1931), but later it was transferred to Lipotactes s. 1. (Hebard, 1922) and returned back (Ingrisch, 1995). Here this species is included in the nominotypical subgenus of the genus Lipotactes and recorded from 
the southeastern part of Sulawesi and a nearest island, but it is useful to note that my males are intermediate between the types of $L$. (L.) concolor (from the southwestern part of Sulawesi) and L. (L.) digitatus; however, the cercus of my males (Fig. 16) has the proximedial hook less curved upwards than in the first species and
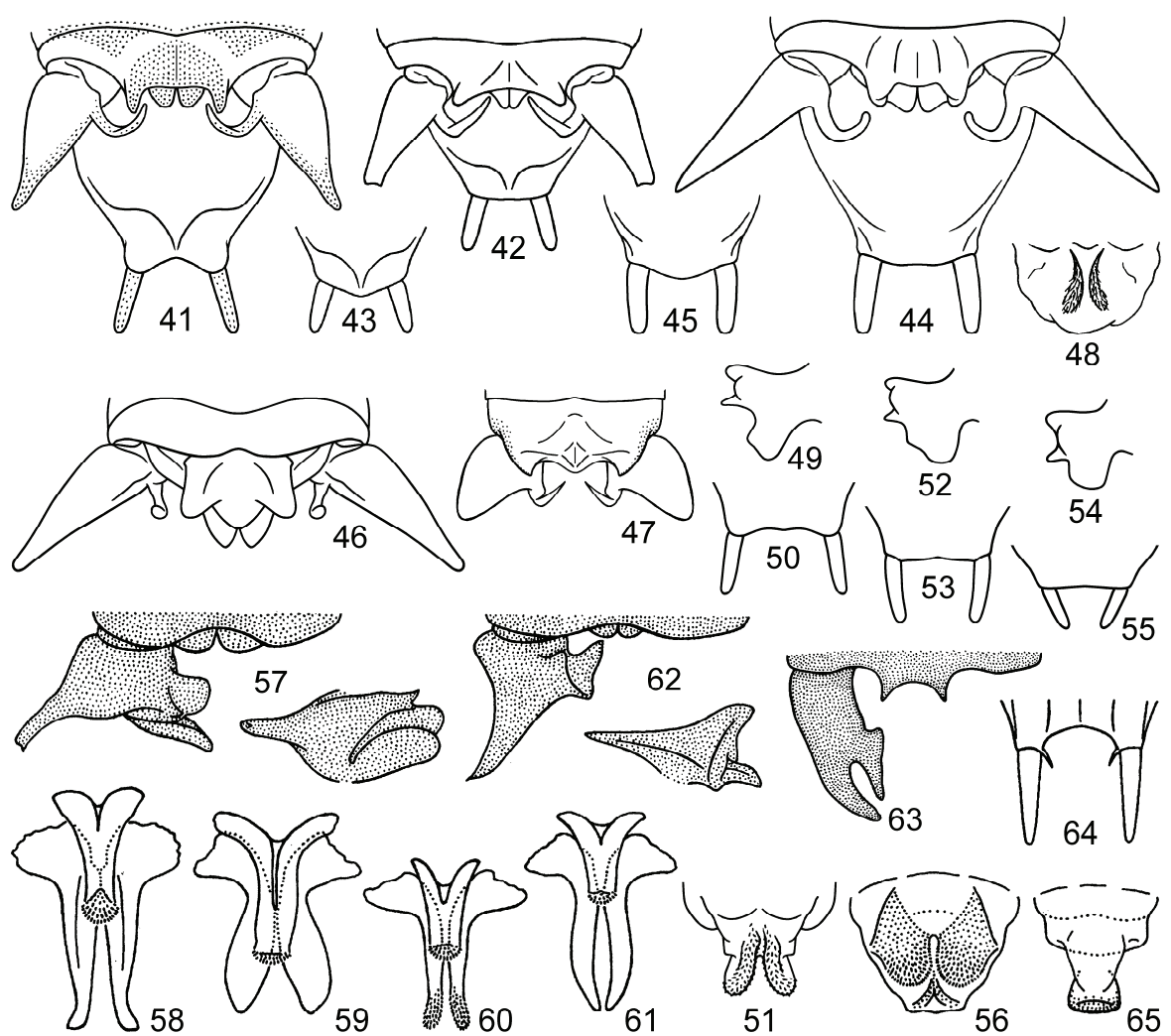

Figs 41-65. Lipotactes spp., schematically: 41 - L. (Prolipotactes) hamatus wartabone subsp. n.; 42, 43 - L. (P.) h. lorelindu subsp. n.; 44, $45-L$. (P.) h. irisovi subsp. n.; $46-L$. (Dialipotactes) maculatus Heb.; 47, 48 - L. (Miolipotactes) minutissimus Gor.; 49-51 - L. (Sublipotactes) khmericus khmericus Gor.; 52, 53 - L. (S.) kh. samkos Ingr.; 54, 55 - L. (S.) kh. saengeri Ingr.; $56-$ L. (S.) ingrischi Gor.; 57, 58 - L. (Eulipotactes) azureus Gor.; $59-L$. (E.) orlovi Gor.; 60 - L. (E.) proximus Gor.; 61 - L. (E.) vietnamicus Gor.; $62-L$. (E.) sinicus (B.-Bien.); 63-65 - L. (Analipotactes) amicus Gor. Male abdominal apex with genital plate $(41,42,44)$ and without it $(46,47)$ from above; distal part of male genital plate from above $(43,45,50,53,55)$ and from below $(64)$; male genitalia from above $(48,51,56,65)$; proximedial lamella of male right cercus from above $(49,52,54)$; male left cercus with some nearest structures (hind part of last tergite and epiproct) from above and without these structure from behind $(57,62)$; this cercus with hind part of last tergite from above (63); sclerites of male genitalia (58-61). [47-49, 51, 56-65-after Gorochov (1993, 1996, 1998, 2008), modified.] 
located more far from the dorsal tubercle than in the second species, and the posteromedian notch of the male genital plate is more similar to that of $L$. $(L$.) digitatus. Thus, the types of $L$. $(L$.) concolor and $L$. ( $L$.) digitatus as well as my specimens may belong to two or three subspecies of the same species.

\section{Subgenus Mortoniellus Griffini, 1909, stat. n.}

Type species Mortoniellus karny Griffini, 1909 (Sumatra).

NOTE. This subgenus was described by Griffini (1909) as a genus for one very large species characterized by the same subgeneric features as all the species of Lipotactes s. str. but distinguished from them by the presence of a pair of distinct sclerotized and denticulate structures in the male genitalia (see Ingrisch, 1885: figs 177-179). This subgenus includes only type species, which was also indicated in the latter paper for Borneo and Malay Peninsula.

\section{Subgenus Prolipotactes Gorochov, subgen. n.}

http://zoobank.org/NomenclaturalActs/7FE2C729-A186-4567-A34B-1EFFB88F992C

Type species Mortoniellus hamatus Karny, 1931 (northwestern part of Sulawesi).

DIAGNOSIS. Male last tergite with short posteromedian lobe widely truncate at apex or having a pair of posterolateral lobules; male epiproct strongly reduced and hidden under above-mentioned lobe; male paraproct with distal part slightly wider than in Lipotactes s. str., somewhat horizontally flattened and rounded or roundly angular at apex; male cercus elongately conical with only proximedial hook and without any additional specializations on this hook or near it (Figs 41, 42, 44); male genitalia completely membranous or with a pair of small semimembranous structures (Fig. 72).

INCLUDED SPECIES. Type species; L. siebersi Ingrisch, 1995 (Indonesian Borneo).

COMPARISON. The new subgenus differs from all the previous subgenera of Lipotactes in the above-mentioned characters of the male cerci.

ETYMOLOGY. This subgeneric name consists of the Latinized Greek prefix "pro-" (before, earlier) and the generic name Lipotactes.

\section{Lipotactes (Prolipotactes) hamatus wartabone Gorochov, subsp. n.}

http://zoobank.org/NomenclaturalActs/108ACA2C-54B4-4895-8D6A-7AA9F4E4DDCD

Figs 41, 66, 67, 85

MATERIAL. Holotype - $\hat{\jmath}$, Indonesia: northeastern part of Sulawesi I., Sulawesi Utara Prov., Bogani Nani Wartabone National Park, environs of Wallace Base Camp near Toraut Vill. (not far from Doloduo Town), 17-25.I 2011, A. Gorochov. Paratype $-\hat{\sigma}$, same data as for holotype. 
DESCRIPTION. Male (holotype). Body moderately small for this genus. Coloration yellowish with following marks: head with four short longitudinal brown stripes on hind half of epicranial dorsum, a pair of brownish dots in dorsolateral corners of clypeus, narrow brownish ring on apical part of each scape, poorly distinct light brownish spots on pedicel, and brown to dark brown antennal flagellum having very sparse and small whitish spots; pronotum with light brown longitudinal median band having brown marks in anterior part, and with a pair of similar (light brown) bands running along lateral edges of disc and not reaching anterior pronotal edge; fore and middle femora with moderately sparse brown to light brown dots; hind femur with dark brown distal part and longitudinal dorsal subdistal stripe as well as dark brown to brown dots around this stripe and brown lines along ventral keels of distal half of this femur; fore and middle tibiae as well as all tarsi and distal part of hind tibia light brown; rest of hind tibia with dark brown to brown longitudinal stripes along dorsal and ventrolateral surfaces as well as with dark spines and spots around their bases (hind spurs also darkened); tegminal membranes semitransparent with light brown tinge in distal parts of tegmina but transparent in rest tegminal parts; abdomen with light brown to brown ornament on dorsal surfaces of seven last tergites as well as with darkened distal halves of cerci (including proximedial hooks) and styles of genital plate (Figs 66, 67). External structure of body very similar to that of $L$. (P.) h. hamatus, but posterior edge of pronotum reaching only apex of tegminal mirror (in $L$. h. hamatus, this edge reaching tegminal apical area; see Ingrisch, 1995: fig. 61), left tegmen as in Fig. 85, last tergite with posterolateral lobules longer and narrower as well as distinctly curved downwards, paraproct rounded at apex, cercus with somewhat longer and clearly thinner apical part and with slightly narrower distal part of its proximedial hook, and genital plate with distinct (but not deep) and rounded posteromedian notch and longer distal thickenings before styles (these thickenings almost reaching each other in median part of this plate; Fig. 41). Genitalia completely membranous.

Variations. Second male with rose marks on rostral region of head, with a pair of poorly distinct rose spots under eyes, and almost without light brown darkening in median part of posterior pronotal half; its tegmina almost hidden under hind pronotal lobe in connection with deformation of pterothorax.

Female unknown.

MEASUREMENTS. Length (in mm). Body 7.5-10; pronotum 4.3-4.5; tegminal parts visible behind pronotum $0.4-0.8$; hind femora $10.5-11$.

COMPARISON. The new subspecies is distinguished from the nominotypical one by the characters listed above: especially by narrower and longer lobules of the male anal plate, longer and thinner cercal apical parts, longer distal thickenings of the male genital plate as well as the presence of a distinct posteromedian notch in this plate.

ETYMOLOGY. This new subspecies is named after Bogani Nani Wartabone National Park where its type locality is situated. 
Lipotactes (Prolipotactes) hamatus lorelindu Gorochov, subsp. n. http://zoobank.org/NomenclaturalActs/164E286C-3BAC-462E-9C81-2A5549423D71

Figs 42, 43, 68-72, 86

MATERIAL. Holotype - $\widehat{\jmath}$, Indonesia: central part of Sulawesi I., Sulawesi Tengah Prov., Lore Lindu National Park, $\sim 75 \mathrm{~km}$ SE of Palu City, environs of Wuasa Vill., $\sim 1000$ m, 7-12.II 2011, A. Gorochov. Paratypes: 7 §, 2 q, same data as for holotype.

DESCRIPTION. Male (holotype). Body slightly smaller than in L. (P.) $h$. wartabone. Coloration of body more or less similar to that of this subspecies, but pronotum yellowish with only three light brown spots in anterior half of disc, hind femur almost without darkened dots and with lighter (brown) areas on distal and dorsal parts, tibiae and tarsi almost yellowish but with brown to light brown marks on hind tibia similar to those of $L$. $(P$.) $h$. wartabone, tegmina and abdomen yellowish with a pair of brown lateral longitudinal bands on abdomen as well as with light brown anal plate and styles of genital plate, and cerci also light brown having apical parts and proximedial hooks slightly darker (almost brown; Figs 68, 69). External structure of body also similar to that of $L .(P)$.$h . wartabone and L$. $(P)$.$h . hamatus,$ but posterior pronotal edge reaching apex of tegminal mirror (as in holotype of $L . h$. wartabone), left tegmen with distal part (including apical area) somewhat narrower than in $L$. $(P$.) $h$. wartabone (compare Figs 85 and 86 ), anal plate with lobules more similar to those of $L$. $(P$.) $h$. hamatus, cercus with apical part distinctly truncate (even barely notched) but with proximedial hook almost as in $L .(P)$.$h . wartabone, and$ genital plate with short (as in $L$. h. hamatus) distal thickenings and with straight posterior edge between styles (Fig. 42). Genitalia membranous but with a pair of short semimembranous lobules located near each other (Fig. 72).

Variations. Some males barely lighter or barely darker; sometimes their posterior pronotal edge slightly not reaching apex of tegminal mirror; genital plate varied from hardy concave to slightly convex between styles (in latter case, this plate rather similar to that of L. h. hamatus; Fig. 43).

Female. General appearance as in males, but pronotum short and with three brown to light brown longitudinal bands, tegmina absent, metanotum with a pair of brown spots in posterolateral corners and with light brown median area turning into almost interrupted median band along dorsum of abdomen (Figs 70, 71), and abdominal apex without any sexual specializations except for small and roundly triangular genital plate as well as moderately short but rather high and acute ovipositor lacking distinct denticles on dorsal and ventral edges.

MEASUREMENTS. Length (in mm). Body: ㅎ 9-10, ㅇ 10-11; pronotum: 3.7-4, , 2.6-2.7; tegminal parts visible behind pronotum, ô 0.8-1.2; hind femora: 万) 9-10, o 10-10.5; ovipositor 5.6-5.8.

COMPARISON. The new subspecies is distinguished from all the other subspecies of this species by the male cercus clearly truncate (even slightly concave) apically (this cercal apex is rounded in L. h. hamatus and very thin in L. h. wartabone), from 
$L$. (P.) h. wartabone by a shorter (or absent) posteromedian notch of the male genital plate and by the presence of semimembranous lobules in the male genitalia, and from $L$. $(P$.) $h$. hamatus with unknown genitalia by the body coloration less uniformly light (except for the hind leg which is similar to that of this subspecies but almost lacking distinct darkened dots on the femur; in L. h. hamatus, these dots are more distinct).

ETYMOLOGY. This subspecies is named after Lore Lindu National Park, in the eastern part of which it was collected.

Lipotactes (Prolipotactes) hamatus irisovi Gorochov, sp. n.

http://zoobank.org/NomenclaturalActs/5AC3E93C-BFAE-440E-9314-316E6CB5AB6C

Figs 44, 45, 73-76, 87

MATERIAL. Holotype - $\hat{\sigma}$, Indonesia: central part of Sulawesi I., Sulawesi Tengah Prov., Lore Lindu National Park, 45 km SSE of Palu City, environs of Tomado Vill. on Lindu Lake, $\sim 1000$ m, 13-17.II 2011, A. Gorochov. Paratypes: 6 males, 2 females, same data as for holotype.

DESCRIPTION. Male (holotype). Body slightly larger than in L. (P.) h. wartabone and $L .(P)$.$h . lorelindu, i. e. medium-sized for this genus. Coloration uniformly$ yellowish (light greenish in living condition), but antennal flagellum light brown to brown, spines and spurs of legs as well as claws and distal lobes of tarsi light brown, and ventral surface of hind tibia as well as distal half of cercus and its proximedial hook intermediate between yellowish and light brown (Figs 73, 74). External structure of body similar to that of $L$. $(P$. $) h$. wartabone, but posterior edge of pronotum reaching distal third of tegminal mirror, left tegmen more similar to that of $L$. $(P$. lorelindu (i.e. its distal part narrower than in L. wartabone) but with slightly wider apical area (Fig. 87), lobules of anal plate located more near each other, cercus somewhat longer, and genital plate almost without thickenings in distal part as well as with more or less straight posteromedian edge between styles (Fig. 44). Genitalia completely membranous.

Variations. Some males with poorly distinct traces of light brownish stripes on head dorsum; sometimes pronotum reaching apex of tegminal mirror, anal plate with slightly shorter lobules, and genital plate with barely convex posteromedian edge (Fig. 45).

Female. General appearance as in males, but abdomen with four anterior tergites having more or less distinct light brown to brown spots on lateral parts (Figs 75, 76); characters of external structure similar to those of $L$. (P.) $h$. lorelindu, but genital plate more transverse and with almost truncate apex (ovipositor practically indistinguishable from that of $L . h$. lorelindu).

MEASUREMENTS. Length (in mm). Body: $\widehat{\sigma} 10-12$, $q$ 11-12.5; pronotum: $\widehat{\sigma}$ 4.5-4.8, ㅇ 3.2-3.3; tegminal parts visible behind pronotum, ô 1-1.5; hind femora: ○ิ 11-12, ㅇ 11.5-12; ovipositor 6-6.5. 
COMPARISON. The new subspecies originates from the western part of Lore Lindu National Park and was collected in another mountain range than $L$. $(P$.) $h$. lorelindu; it differs from the latter subspecies in the male cercal apex normal, and in the male genitalia completely membranous. From $L$. $(P$.) $h$. wartabone, it is distinguished by some characters of the external structure listed above, and from $L$. $(P$.) $h$. hamatus by the male anal plate having its lobules located more near each other, by the male cercus longer and with thinner apical part, and by the male genital plate lacking distinct distal thickenings. From all these subspecies, the new one also differs in the hind femur distinctly more uniformly light.

ETYMOLOGY. This subspecies is named in memory of the big nature lover Grigory Irisov who organized a trip to Lore Lindu National Park in 2011.

Subgenus Dialipotactes Gorochov, subgen. $n$.

http://zoobank.org/NomenclaturalActs/5BDBAB22-B9F3-4662-A0A6-D25CF52EEB68 Type species Lipotactes maculatus Hebard, 1922 (Singapore).

DIAGNOSIS. Rostrum of head almost lamellar (laterally compressed), unique for Lipotactes s. 1. Male abdominal apex as in Lipotactes s. str., but epiproct with additional lateral lobules, paraproct with roundly angular projection at apex, and male cercus as in Prolipotactes (i.e. without dorsal tubercle at base of proximedial hook or near it; Fig. 46) or possibly with proximedial hook moved to subapical part of cercus. land).

INCLUDED SPECIES. Type species; possibly L. minutus Ingrisch, 1995 (Thai-

COMPARISON. The new subgenus differs from all the congeners in the head rostrum lamellar, and from the nominotypical subgenus in the abdominal characters listed above. From the subgenus Mortoniellus, it is distinguished by the male cercus without a dorsal tubercle at the base of the proximedial hook or near it, and by the male genitalia completely membranous; and from Prolipotactes, by the male last tergite lacking a distinct posteromedian lobe, and by the male epiproct normal in the size (rather large and well visible) and with a pair of lateral lobules.

ETYMOLOGY. This subgeneric name consists of the Latinized Greek prefix "dia-" (divided, separated) and the generic name Lipotactes.

\section{Lipotactes (Dialipotactes) maculatus Hebard, 1922}

Fig. 46

MATERIAL. Malaysia: $10 \hat{\jmath}, 9$, Pahang State, Tioman I. not far from Mersing City (Johor State) on Malay Peninsula, environs of Juara Vill. (eastern coast), 6-14.IV 2010, A. Gorochov, M. Berezin, E. Tkatsheva; 1 đै, same data, but 10-18.IV 2011, M. Berezin.

NOTE. These specimens are very similar to the descriptions of this species by Hebard (1922) and Ingrisch (1995). Thus, this species, previously known from only Singapore, is here indicated for a new locality situated not very far from its type locality. 


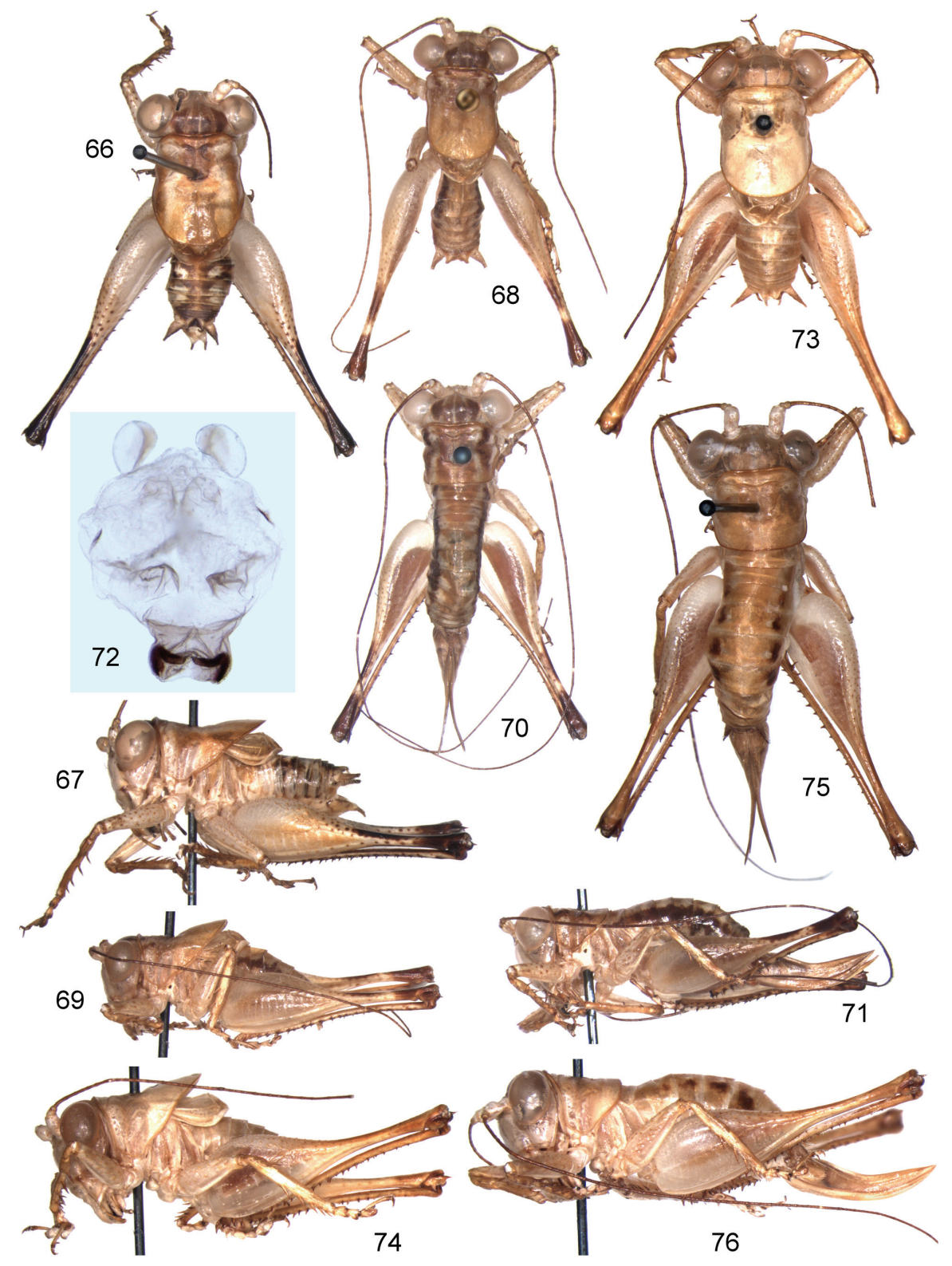

Figs 66-76. Lipotactes spp.: 66, 67 - L. (Prolipotactes) hamatus wartabone subsp. n.; 68-72-L. (P.) h. lorelindu subsp. n.; 73-76-L. (P.) h. irisovi subsp. n. Body of male (66$69,73,74)$ and of female $(70,71,75,76)$ from above or from side; male genitalia from above (72). 
Subgenus Neolipotactes Gorochov, subgen. $\mathbf{n}$.

http://zoobank.org/NomenclaturalActs/EDFB83B3-0C44-446A-9781-286DA1CCE7FF

Type species Lipotactes montanus Ingrisch, 1990 (Thailand).

DIAGNOSIS. Rostrum of head not lamellar, typical of this genus; male last tergite with a short posteromedian lobe having concave or almost straight posterior edge (this lobe possibly originating from basal part of epiproct more or less fused with last tergite but separated from more distal part of epiproct by strong transverse fold); male epiproct not reduced, without lateral lobules, with small (but distinct) roundly triangular distal part directed more or less downwards; male paraproct with wide, horizontally lamellar and apically rounded projection at apex; male cercus elongately subcylindrical, with short or long apical spine directed medially, with more strong ventromedial spine directed also medially $(?=$ proximedial hook in previous subgenera) but located almost in middle part of cercus, and with dorsomedial longitudinal keel on proximal part of cercus (?= dorsal tubercle at base of proximedial hook or near it in Lipotactes s. str. and Mortoniellus) (Fig. 25); male genitalia completely membranous.

INCLUDED SPECIES. Type species; L. silvestris Ingrisch, 1990 (Thailand).

COMPARISON. The new subgenus differs from all the previous subgenera in wide and horizontally lamellar projections of the male paraprocts as well as in the presence of apical spines at the male cerci; additionally it is distinguished from Lipotactes s. str. by the presence of a posteromedian lobe on the last male tergite, from Mortoniellus by the same character and the male genitalia completely membranous, from Prolipotactes by the possible presence of the dorsal tubercle near the proximedial hook in the male cercus, and from Dialipotactes by the latter character and the presence of a posteromedian lobe on the male last tergite as well as the absence of a pair of lateral lobules on the male epiproct.

Lipotactes (Neolipotactes) montanus Ingrisch, 1990

Fig. 25

MATERIAL. Laos: 4 ô, 6 o, Vientiane Prov., 70 km NWW of Vientiane City, Nam Lik Eco Vill. on Nam Lik River, $18.61469^{\circ} \mathrm{N}, 102.40847^{\circ} \mathrm{E}, \sim 200 \mathrm{~m}$, 10-30.VI 2017, A. Gorochov, M. Omelko.

NOTE. These specimens are very similar to the original description of this species (Ingrisch, 1995). Here the species is recorded from Laos for the first time.

Subgenus Miolipotactes Gorochov, subgen. n.

http://zoobank.org/NomenclaturalActs/8C0A4814-766E-4EB7-911E-ECF904AA7EE8

Type species Lipotactes minutissimus Gorochov, 2008 (Malay Peninsula).

DIAGNOSIS. Rostrum of head not vertically lamellar; male last tergite without posteromedian lobe but with a pair of posterior angular projections around epiproct; male epiproct normal (roundly triangular, without any folds or lobules) but basally 
more or less fused with posterior edge of last tergite (between above-mentioned projections) and directed downwards; male paraproct short, rounded; male cercus very short, thick (especially in proximal part), with proximedial hook strongly and almost angularly curved but lacking any tubercles on its base or near it (Fig. 47); male genitalia membranous with a pair of semimembranous stripes (Fig. 48). However, in one species possibly also belonging to this subgenus, posterolateral corners of dorsal part of male last tergite practically undeveloped, male epiproct probably separated from latter tergite, and male genitalia unstudied (see Ingrisch, 2021: fig. 4, E, F).

INCLUDED SPECIES. Type species; possibly L. angulatus Ingrisch, 2021 (Central Vietnam).

COMPARISON. The new subgenus is distinguished from all the previous subgenera of this genus by the male cercus very short and basally thick as well as with the proximedial hook lacking any tubercles on its base or near it (as in Prolipotactes and Dialipotactes) but strongly and angularly curved. From Prolipotactes, the new subgenus also differs in the absence of a posteromedian lobe of the male last tergite, and from Dialipotactes, in the male epiproct lacking any lateral lobules.

ETYMOLOGY. The new subgeneric name consists of the Latinized Greek prefix "mio-" (smaller) and the generic name Lipotactes.

Subgenus Sublipotactes Gorochov, subgen. $\mathbf{n}$.

http://zoobank.org/NomenclaturalActs/E0A02D0C-290A-4FE7-B147-877931DB33AE

Type species Lipotactes khmericus Gorochov, 1998 (Cambodia).

DIAGNOSIS. Head rostrum not vertically lamellar; male last tergite without distinct posteromedian lobe and without a pair of posterior projections on dorsum; male epiproct normal (roundly triangular and without any folds or lobules); male paraproct approximately as in Neolipotactes; male cercus elongately conical, with rather thin distal part and almost lamellar widened lobule (lamella) located at place of proximedial hook of previous subgenera (instead it), and without any tubercles on basal part of this lamella or near it; male genitalia membranous with a pair of semimembranous lobes (lobules) having numerous small setae (Figs 51, 56).

INCLUDED SPECIES. Type species; L. ingrischi Gorochov, 1996 (Central Vietnam); L. discus Ingrisch, 2021 (Cambodia).

COMPARISON. The new subgenus is distinguished from all the previous congeners by the male cercus having a widened lamellar proximedial lobule (lamella) instead the proximedial hook and lacking any tubercles on the base of this lamella and near it, and additionally from Prolipotactes, Miolipotactes and Dialipotactes, in the both male last tergite and male epiproct lacking any lobes, projections and lobules.

ETYMOLOGY. This subgeneric name consists of the Latin prefix "sub-" (under, very near) and the generic name Lipotactes. 

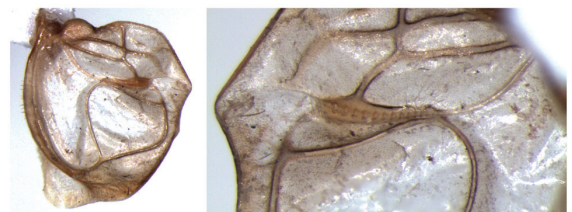

77
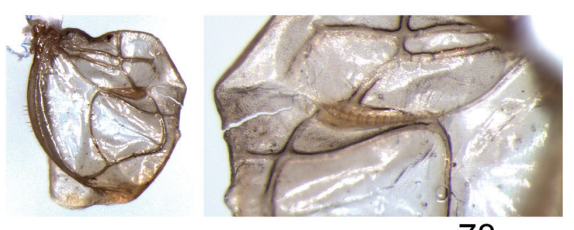

78
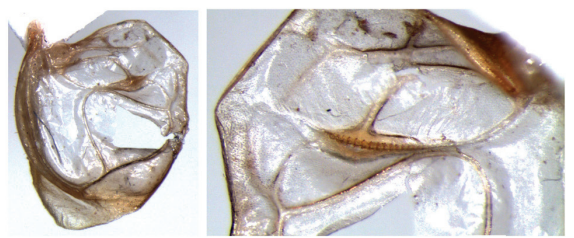

79
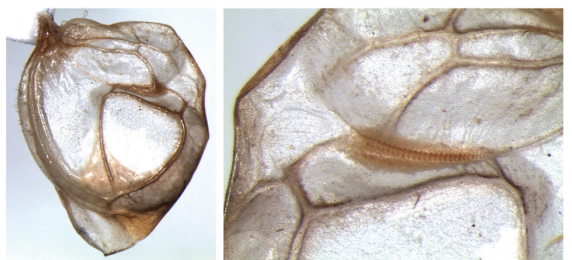

80
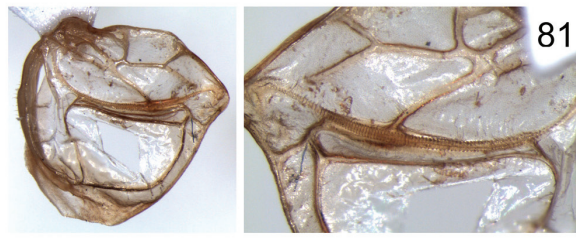

81
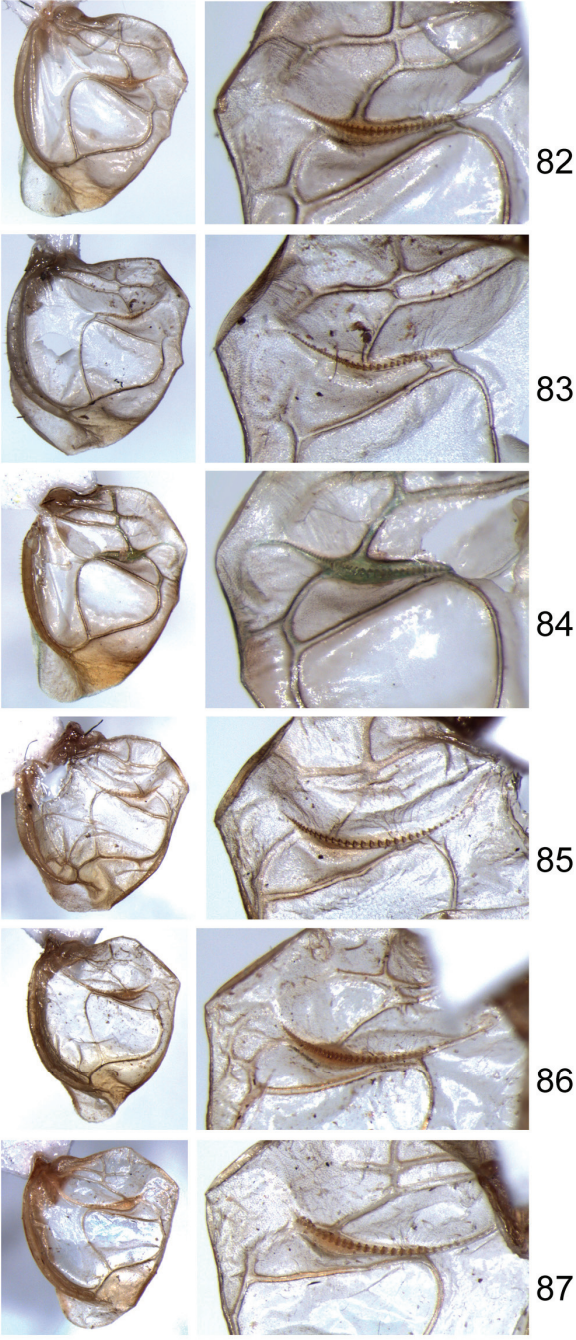

Figs 77-87. Lipotactes spp.: 77 - L. (Lipotactes) alienus lambir subsp. n.; 78 - L. (L.) a. similajau subsp. n.; $79-$ L. (L.) a. kubah subsp. n.; $80-$ L. (L.) sumatranus sp. n.; $81-L$. (L.) kabili Tan et al.; 82-84 - L. (L.) virescens Ingr. from Malay Peninsula (82 - Thailand; 83 Malaysia) and from Sumatra (84); 85 - L. (Prolipotactes) hamatus wartabone subsp. n.; $86-$ L. (P.) h. lorelindu subsp. n.; $87-L .(P)$.$h . irisovi subsp. n. Male left tegmen from above$ (left photo), and its stridulatory vein from below (right photo).

\section{Lipotactes (Sublipotactes) khmericus Gorochov, 1998} Figs 49-55

MATERIAL. Cambodia: $7 \hat{\jmath}, 6$, western part, environs of Sihanoukville Town near Siam Bay, secondary forest, 22-26.VIII 2003, A. Gorochov, L. Anisyutkin; 2 ○, 
1 , 10-15 km NEE of Sihanoukville Town, environs of waterfall, $200 \mathrm{~m}$, secondary forest, 11-12.IX 2003, A. Gorochov; $3 \hat{\delta}, 2$, southern part of Elefan Mts, Bokor National Park on Phnom-Bokor Mt, 700-1000 m, forest, 18-22.IX 2003, A. Gorochov, M. Berezin; 4 ふै, 3 , central part of Elefan Mts, $100 \mathrm{~km}$ NE of Sihanoukville Town, environs of Styeng-Chkhral Vill., 300-500 m, forest, 27.VIII-6.IX 2003, A. Gorochov, L. Anisyutkin; 1 స, 1 q, northern part of Elefan Mts, $150 \mathrm{~km}$ NNE of Sihanoukville Town, Kiri-Rom National Park, $\sim 600-800$ m, remnants of forest, 7-10.X 2003, A. Gorochov, M. Berezin.

NOTE. These specimens are very similar to the holotype of $L$. (S.) khmericus, but the medial cercal lamella of their males are less deeply notched near its apical spinule (compare Figs 49 and 52, 54). The males from Elefan Mts have the genital plate styles almost as long as in this holotype (Figs 50, 53), and some of them are practically indistinguishable from males of L. samkos Ingrisch, 2021 in the cercal lamella (Fig. 52). The other males from my material are with these styles somewhat shorter (Fig. 55), and these males are very similar to those of L. saengeri Ingrisch, 2021 in the shape of this lamella (Fig. 54). However, all these differences are very insignificant and only imply a subspecies status. So, here I subdivide $L$. (S.) khmericus into three subspecies: nominotypical one (Figs 49,50) characteristic of the eastern part of Cambodia; L. (S.) kh. samkos stat. n. (Figs 52, 53) living in mountains of the western part of Cambodia; L. (S.) kh. saengeri stat. n. (Figs 54, 55) distributed in the western sea coast of Cambodia and the nearest part of Thailand.

\section{Lipotactes (Sublipotactes) discus productus Ingrisch, 2021, stat. n.}

MATERIAL. Vietnam: $1 \hat{\jmath}$, Dong Nai Prov., Vinh Cuu Distr., Vinh Cuu Nature Reserve (= Ma Da Forest), TW Cuc Forest Station, $11^{\circ} 22^{\prime} 51^{\prime \prime} \mathrm{N}, 107^{\circ} 03^{\prime} 44^{\prime \prime} \mathrm{E}$,

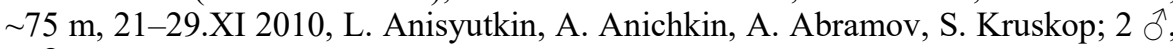
2 , same province, Cat Tien National Park, 15-20.XI 2010, L. Anisyutkin, A. Anichkin.

NOTE. Recently Ingrisch (2021) described two closely related taxa distinguished from each other mainly by the male cerci with somewhat different lengths of their thin distal parts: L. discus Ingrisch, 2021 from Cambodia and L. productus Ingrisch, 2021 from South Vietnam. However, this difference, as it seems to me, is insufficient for the species level, and more corresponds subspecies one. Thus, here these taxa are considered as two subspecies of the same species: $L$. $(S)$.$d . discus having$ shorter male cerci and distributed in Cambodia; $L$. $(S$.) d. productus stat. n. having longer male cerci, described from Cat Tien National Park in South Vietnam and recorded here from a new but nearest locality.

\section{Subgenus Eulipotactes Gorochov, subgen. n.}

http://zoobank.org/NomenclaturalActs/A28D51FC-3606-4781-9E3A-36CB037F08B5 Type species Lipotactes azureus Gorochov, 1996 (North Vietnam).

DIAGNOSIS. Head rostrum not vertically lamellar; male last tergite without any posterior lobes and projections; male epiproct almost normal, roundly triangular and not reduced but directed downwards and with a pair of basal inflations often almost 
touching each other; male paraproct approximately as in Neolipotactes and Sublipotactes; male cercus with strongly thickened proximal half (or two thirds) having two large and often thick (massive) proximedial processes $(?=$ proximedial hook and tubercle in some previous subgenera) (Figs 57, 62); male genitalia with three large elongate sclerites (Figs 58-61).

INCLUDED SPECIES. Type species; L. vietnamicus Gorochov, 1993 (North Vietnam); L. orlovi Gorochov, 1996 (North Vietnam); L. proximus Gorochov, 1996 (North Vietnam); L. dorsaspina Chang, Shi et Ran, 2005 (South China), but possibly only subspecies of $L$. azureus; L. serratus Ingrisch, 2021 (North Vietnam); possibly Mortoniellus sinicus Bey-Bienko, 1959 (South China) and L. tripyrga Chang, Shi et Ran, 2005 (South China).

COMPARISON. The new subgenus clearly differs from all the previous congeners in the absence of any lobes and projections on the male last tergite in combination with the male epiproct normal but having a pair of basal inflations, the male cercus having strongly thickened proximal half (or two thirds) and two large proximedial processes, and the male genitalia having three large and elongate sclerites.

ETYMOLOGY. The new subgeneric name consists of the Latinized Greek prefix "eu-" (good, true) and the generic name Lipotactes.

Subgenus Analipotactes Gorochov, subgen. $\mathbf{n}$.

http://zoobank.org/NomenclaturalActs/E1 193F98-C765-497A-B456-C4AE54528327

Type species Lipotactes amicus Gorochov, 1993 (Central Vietnam).

DIAGNOSIS. Head rostrum not vertically lamellar; male last tergite with short but distinct posteromedian lobe having a pair of angular (almost spinule-like) projections posterolaterally; male epiproct medium-sized, roundly trapezoidal but rather narrow, directed downwards and slightly forwards; male paraproct wide but somewhat elongate, horizontally lamellar, with almost roundly angular apical part more or less curved upwards; male cercus elongate, with medial lamellar lobule (lamella) more or less similar to that of Sublipotactes but located in distal half of cercus, and with distal (lateral) cercal part somewhat curved medially and slightly widened apically (but this widening visible only from behind or from side); male genital plate with a pair of distinct medial spinules near bases of styles (this character unique for this genus; Fig. 64); male genitalia membranous with almost semimembranous apical part (Fig. 65).

INCLUDED SPECIES. Type species only.

COMPARISON. The new subgenus is distinguished from all the other congeners by the male last tergite having a distinct posteromedian lobe, in combination with the male cercus having a medial lamella in its distal half (instead proximedial lamella, hook or spine) as well as the distal (lateral) part of this cercus curved medially and slightly widened apically, and with the presence of a pair of spinules near the bases of the styles in the male genital plate.

ETYMOLOGY. This subgeneric name consists of the Latinized Greek prefix "ana-" (against, anew) and the generic name Lipotactes. 


\section{Lipotactes (Analipotactes) amicus Gorochov, 1996}

Figs 63-65

MATERIAL. Vietnam: $6 \hat{\jmath}, 9$ ㅇ, Gia Lai Prov., $20 \mathrm{~km} \mathrm{~N}$ of Kannack Town, environs of Buon Luoi Vill., 3-19.XI 1993, A. Gorochov; 8 गे, 4 , , same data, but 14.IV-1.V 1995, A. Gorochov; 1 ㅇ, same province, $\sim 40 \mathrm{~km} \mathrm{~N}$ of Kannack Town, environs of Tram Lap Vill., 1-14.XII 1988, A. Gorochov; 1 $\widehat{\jmath}, 2$ ㅇ, same data, but 12-14.XI 1993, A. Gorochov; 6 ऽ, 7 , same province, Ka Bang Distr., environs of Krong Pa Vill., IX 1997, N. Orlov.

NOTE. The locality in the Ka Bang District is a new locality for this species; the other specimens are from the localities of $L$. (A.) amicus type series.

\section{ACKNOWLEDGEMENTS}

The author is grateful to the collectors of these insects. The study was performed in the frames of the state research project No. AAAA-A19-119082990107-3 (Russian Federation).

\section{REFERENCES}

Brunner-Wattenwyl C. 1898. Orthopteren des Malayischen Archipels, gesammelt von Prof. Dr. W. Kukenthal in den Jahren 1893 und 1894. Abhandlungen der Senckenbergischen Naturforschenden Gesellschaft, 24: 193-288, pl. 16-20.

Gorochov A.V. 1993. Two new species of the genus Lipotactes from Vietnam (Orthoptera: Tettigoniidae). Zoosystematica Rossica, 2(1): 59-62.

Gorochov A.V. 1996. New and little known species of the genus Lipotactes Br.-W. (Orthoptera, Tettigoniidae) from Vietnam. Entomologicheskoe Obozrenie, 75(1): 32-38. [In Russian]

Gorochov A.V. 1998. A new species of the genus Lipotactes from Cambodia (Orthoptera: Tettigoniidae). Zoosystematica Rossica, 7(1): 132.

Gorochov A.V. 2008. A new species of the genus Lipotactes from Malacca (Orthoptera: Tettigoniidae). Zoosystematica Rossica, 17(2): 71-72.

Gorochov A.V. 2020. Taxonomy of the katydids (Orthoptera: Tettigoniidae) from East Asia and adjacent islands. Communication 13. Far Eastern Entomologist, 400: 1-36. DOI: https://doi.org/10.25221/fee.400.1

Griffini A. 1909. Intorno a due Ortotteri saltatori raccolti a Sumatra dal Dr. W. Morton. Wiener entomologische Zeitung, 28: 105-109.

Hebard M. 1922. Studies in Malayan, Melanesian and Australian Tettigoniidae (Orthoptera) Proceedings of the Academy of Natural Sciences of Philadelphia, 74: 121-299, pl. 11-22.

Ingrisch S. 1995. Revision of the Lipotactinae, a new subfamily of Tettigonioidea. Entomologica scandinavica, 26: 273-320.

Ingrisch S. 2021. New species and records of the genus Lipotactes (Orthoptera: Tettigoniidae: Lipotactinae) from Vietnam, Cambodia, and Thailand. Journal of Orthoptera Research, 30(1): 51-65. DOI: https://doi.org/10.3897/jor.30.58095

Karny H.H. 1931. Orthoptera Celebica Sarasiniana. I. Saltatoria: Fam. Tettigoniidae. Treubia, 12(Supplement): 4-140.

Tan M.K., Ingrisch S., Wahab R.B.H.A., Japir R. \& Chung A.Y.C. 2020. Ultrasonic bioacoustics and stridulum morphology reveal cryptic species among Lipotactes big-eyed katydids (Orthoptera: Tettigoniidae: Lipotactinae) from Borneo. Systematics and Biodiversity, 18(5): 510-524. DOI: https://doi.org/10.1080/14772000.2020.1769223 